\title{
Há uma Nova Economia do Desenvolvimento?
}

\author{
Bianca Imbiriba Bonente ${ }^{1}$ \\ Niemeyer Almeida Filho ${ }^{2}$
}

\begin{abstract}
Resumo: Nos termos de Albert Hirschman, nasce no período do pós-guerra uma disciplina no interior da ciência econômica conhecida como Economia do Desenvolvimento. Entretanto, se por um lado o "desenvolvimento econômico" emergiu como uma temática de extremo sucesso no campo da economia, por outro, em um período relativamente curto de tempo, assiste-se ao seu declínio. Após alguns anos de ausência, o desenvolvimento econômico volta a ser debatido nos anos de 1980, incorporando novas temáticas. Nesse sentido, o presente artigo busca, através de um resgate da transmutação histórica da discussão de desenvolvimento econômico numa discussão fragmentada e de uma análise da natureza mesma dessa fragmentação, discutir a existência, ou não, de uma Nova Economia do Desenvolvimento.
\end{abstract}

Palavras-chave: desenvolvimento econômico; Economia do Desenvolvimento; Nova Economia do Desenvolvimento.

\section{Is there a New Development Economics?}

\begin{abstract}
In the terms of Albert Hirschman, a discipline in the interior of the economics known as Development Economics, was born in the postwar period. However, if "economic development" emerged as a theme of extreme success, in a relatively short period of time it has faded. Absent from economic debate for some time, economic development came back in the 1980s, incorporating new issues by rescuing the historical mutations of development economics into a fragmented quarrel and analyzing the nature of this process. The present article aims to debate whether New Development Economics exists or not.
\end{abstract}

Key words: economic development; Development Economics; New Development Economics.

JEL: B19; Fo2; No1; O10

1 Mestre em Economia pelo PPGE do IE-UFU. Aluna do Doutorado em Economia da UFF. E-mail: biancaimbiriba@gmail.com.

2 Professor associado do IE-UFU. Doutor em Economia pelo IE-UNICAMP. E-mail: nafilho@ufu.br. 


\section{Introdução}

Nos termos de Albert Hirschman, nasce no período do pós-guerra, mais especificamente nos anos de 1950, uma disciplina no interior da ciência econômica conhecida como Economia do Desenvolvimento. Essa nova disciplina obteve imenso sucesso em termos de produção bibliográfica e repercussão social, servindo de base para a formulação de políticas nacionais até os anos de 1960. Entretanto, em um período relativamente curto de tempo, assistese ao seu declínio, não apenas no campo estritamente teórico, mas também na medida em que havia se transformado em prática e discurso político. $\mathrm{O}$ mesmo Hirschman, um dos responsáveis pelo interesse acadêmico e social da disciplina, em um artigo de grande repercussão, sustenta que a disciplina do desenvolvimento econômico havia se esgotado. ${ }^{3}$

Esse período de crise na disciplina (que vai de meados dos anos de 1960 a meados dos anos de 1980, aproximadamente) é importante, pois nele ocorre uma mudança de paradigma do processo de acumulação de capital em nível global. Aqui estamos nos referindo às mudanças de padrão tecnológico de produção e, também, às mudanças que ocorrem em nível das finanças globais. 4

No entanto, nos anos de 1980, gradualmente, volta à tona o debate sobre desenvolvimento no âmbito das agências multilaterais, sobretudo do Banco Mundial, no bojo das discussões a respeito da deterioração ambiental e da renitente presença da pobreza e da fome em nível global, não obstante a superação definitiva da incapacidade da produção de alimentos em fazer frente às necessidades humanas. Ficavam evidentes as disparidades de condições de vida. A velha noção do desenvolvimento econômico parecia limitada para dar conta da amplitude desses problemas.

$\mathrm{O}$ resultado desse processo é surpreendente. O tema do desenvolvimento tornou-se certamente mais amplo no conjunto das suas questões do que havia sido nos anos de 1950, principalmente devido à incorporação de novas temáticas. Ao substantivo "desenvolvimento" são apensados inúmeros adjetivos, conferindo ao termo uma suposta multiplicidade. Essa fragmentação interna à disciplina deu origem, no entanto, a uma série de subtemáticas e delimitações de escala que tornaram o campo do desenvolvimento mais complexo e difícil de ser compreendido na sua dimensão global.

\footnotetext{
3 O artigo em questão é "Ascensão e declínio da Economia do Desenvolvimento" (Revista de Ciências Sociais, v. 25, n. 1, 1982). Apesar do notável reconhecimento que teve o autor dentro da temática do desenvolvimento econômico (uma de suas principais obras, "A estratégia de desenvolvimento econômico" (1961), ofereceu contribuições importantes ao estudo do subdesenvolvimento), a escolha de Hirschman para iniciar esse artigo se justifica na medida em que o autor demonstrou grande preocupação com a evolução da disciplina, oferecendo no artigo supracitado uma avaliação consistente dos principais limites teóricos e práticos com que esse campo de estudo se deparou.

4 A referência à mudança no padrão tecnológico é importante, pois altera significativamente a base sobre a qual as teorias de desenvolvimento são formuladas.
} 
Fernando Henrique Cardoso (1995) faz referência a esse processo de fragmentação como sendo o resultado de um mundo que havia se tornado mais complexo, no qual as discussões de desenvolvimento econômico não caberiam mais, sobretudo se fosse considerado o fato de que o espaço supranacional tornava-se um domínio hegemônico na discussão das ações de temporalidade mais longa. Por isso, ele sustenta que o desenvolvimento é o mais político dos temas. E apesar dos problemas que a atual perspectiva do desenvolvimento pode engendrar, considera o autor que tal mudança "constitui claramente um ganho”. Certamente, essa é uma opinião a ser problematizada.

Lançando um olhar mais atento sobre o processo acima indicado, o presente artigo se concentra em dois tipos de questões. A primeira diz respeito a uma transmutação histórica de uma discussão de desenvolvimento econômico numa discussão fragmentada, nos termos apresentados acima. Uma segunda diz respeito à natureza mesma da fragmentação, ou a um levantamento das linhas principais de discussão, procurando aferir uma possível lógica de composição. Uma pergunta poderia traduzir a perspectiva: há uma nova economia do desenvolvimento?

Com o intuito de elucidar essa discussão, o trabalho está organizado em três seções. Primeiramente, é importante ressaltar, ainda que de forma breve, as concepções fundamentais e correntes principais dessa que ficou conhecida como Economia do Desenvolvimento. Feito isso, uma segunda seção é dedicada ao "declínio histórico" da disciplina, apresentando os impasses práticos com que esta se deparou a partir do final dos anos de 1960. Por fim, na terceira e última seção discutiremos como a conjunção dos impasses práticos e teóricos determina uma redefinição dos parâmetros da discussão sobre desenvolvimento, mostrando algumas das novas contribuições teóricas nesse campo de estudo.

\section{A Economia do Desenvolvimento}

Como indicado acima, nasce no período do pós-guerra uma disciplina no interior da ciência econômica conhecida como Economia do Desenvolvimento, composta pelo pensamento anglo-saxão e pelos autores latino-americanos da CEPAL (componentes significativos dessa onda desenvolvimentista que tomou conta do pensamento econômico mundial).

Entre os autores do primeiro grupo, destacam-se os trabalhos pioneiros de Rosenstein-Rodan (1969) e Ragnar Nurkse (1957), influenciados fundamentalmente pelo conceito de "crescimento equilibrado", presente no modelo Harrod-Domar. Walter Rostow (1978) e Artur Lewis (1969) seguem a mesma linha e, sob alguns aspectos, vão além dos antecessores. Uma crítica a essa noção de crescimento equilibrado é fornecida por Gunnar Myrdal (1965) e Albert Hirschman (1961), que se destacam em sua época com a tese da "cau- 
sação cumulativa"5 e do "crescimento desequilibrado" - e, nesse sentido, são autores marcados pela maior proximidade ao estruturalismo latinoamericano.

O pensamento clássico da CEPAL pode, inegavelmente, ser considerado parte importante da tradição crítica ao pensamento ortodoxo-conservador. ${ }^{6}$ Além disso, como ressalta Marini (1992:74):

(...) a Cepal, partindo da teoria do desenvolvimento, tal como fora formulada nos grandes centros, introduz nela modificações, que representarão sua contribuição teórica própria, original, e que tornarão o desenvolvimentismo latino-americano um produto, mas não uma simples cópia da teoria do desenvolvimento.

No entanto, de uma forma geral, a Cepal serviu aos propósitos de difusão da teoria do desenvolvimento, e as limitações de seu pensamento foram, em boa parte, um "tributo à relação umbilical que ela não deixou nunca de manter com a teoria do desenvolvimento" (Marini 1992:77).

As restrições próprias a um artigo da natureza que pretendemos produzir impedem um resgate mais profundo dessa que foi a "velha" Economia do Desenvolvimento. Contudo, há referências consagradas que podem cumprir a função de base para uma comparação do que seria a Nova Teoria do Desenvolvimento. Há pelo menos cinco livros que resgatam as contribuições críticas mais importantes ao tema, todos eles publicados no breve período de 1989-1990: Development Theory and the Three Worlds (Hettne 1990), Economic Theories of Development (Hunt 1989), Latin American Theories of Development and Underdevelopment (Kay 1989), Theories of Development (Larrain 1989) e Democracy and Development in Latin America (Lehmann 1990). Além disso, há coletâneas importantes que sintetizam as teorizações daqueles que são os principais atores do debate sobre o desenvolvimento dos anos de 1950 e 1960: Paradigms in Economic Development (Kanth 1994), The Political Economy of Development and Underdevelopment (Jameson \& Wilber 1996) e Alternative Strategies for Economic Development (Griffin 1999).

Dificulta ainda esse resgate o fato das teorias desenvolvimentistas apresentarem diferenças importantes que não permitem afirmar a existência de um todo homogêneo. Mais empenhados em compreender as especificidades das economias subdesenvolvidas, para então propor saídas dessa condição, parece ser verdade que os autores latino-americanos são os que mais destoam dos

\footnotetext{
5 Essa noção de causação cumulativa pode ser encontrada também no modelo Harrod-Domar, que, após descrever como seria o crescimento equilibrado - conceito, como apontado anteriormente, utilizado por Nurkse em sua análise - destaca alguns problemas quanto a sua viabilidade. O chamado segundo problema de Harrod pretende mostrar, de forma análoga à causação cumulativa de Myrdal, como "Desvios da taxa verdadeira de crescimento numa economia do tipo Harrod da taxa garantida (...) longe de serem autocorretivos, são cumulativos de fato."(Jones 1979:69)

6 No pensamento latino-americano, destacam-se os trabalhos clássicos de Prebisch (2000), Furtado (1969, 1979), Lessa (1983) e Tavares (1973). As sistematizações produzidas por Bielschowsky (1996, 1998), Mantega (1990) e Rodríguez (1981) também são de grande valia para o entendimento dessa corrente de pensamento.
} 
demais desenvolvimentistas. Nesse sentido, observa-se também a influência exercida pelo pensamento desse grupo de teóricos sobre a prática dos governos da América Latina.

Mas a despeito das diferenças pontuais, compartilha toda a corrente desenvolvimentista uma mesma crença, um mesmo ideal, de superar o subdesenvolvimento através da maior aproximação a um modelo que se mostrou eficiente enquanto motor do desenvolvimento americano. Não que todos buscassem ser meras reproduções dessa sociedade capitalista tomada como referência; ao contrário, parcela considerável das teorias procurou entender os entraves ao desenvolvimento em uma tentativa de oferecer propostas condizentes com as especificidades de cada formação social. No entanto, as saídas apontadas se aproximam em um único aspecto: todas crêem ser necessário ao desenvolvimento dar início a esse processo capitalista de industrialização. Compartilha-se um mesmo ideal de progresso.

De uma forma geral, é possível reconhecer em todos os teóricos do desenvolvimento a utilização das receitas do desenvolvimento das nações capitalistas pioneiras para propor saídas aos países subdesenvolvidos. Por fim, se é verdade que em Myrdal e Hirschman fica mais explícita a importância da atuação do Estado, mesmo em autores como Nurkse e Rostow é possível perceber a referência ao Estado nacional.

Assiste-se, no entanto, no bojo da crise dos anos de 1970 e da ascensão da ideologia neoliberal, ao declínio da Economia do Desenvolvimento. Conforme se pretende mostrar nas próximas seções, as transformações do capitalismo, que se observam a partir de então, irão mudar os rumos dessa disciplina.

\section{O declínio histórico}

O declínio do "desenvolvimento econômico" foi formulado por Hirschman a partir dos resultados concretos da aplicação das políticas de desenvolvimento gestadas na fase áurea do capitalismo no pós-guerra, e de uma análise das condições sob as quais a disciplina emergiu.7 De acordo com Hirschman (1982:6), a emergência da Economia do Desenvolvimento ocorreu como resultado da conjunção de distintas correntes ideológicas que, apesar de ter se mostrado produtiva inicialmente, criou problemas para o futuro:

\footnotetext{
7 Num mesmo sentido, pode ser citado o trabalho de Arthur Lewis (1984) "The State of Development Theory" (The American Economic Review, Mar. 74(1):1-10), embora neste não haja a idéia de um declínio completo da disciplina, como está explicitamente sustentado em Hirschman. Lewis, também um dos teóricos fundadores da disciplina, acredita que Hirschman oferece um obituário precoce, e que a Economia do Desenvolvimento, apesar de não estar em seus melhores dias, "está viva e bem". Em Amartya Sen (1985), pode ser encontrada uma posição diferente, já que ele sustenta que a Teoria do Desenvolvimento cumpriu avanços significativos.
} 
Primeiro, em razão de sua feição ideológica heterogênea, a nova ciência estava submetida a tensões que se mostrariam explosivas na primeira oportunidade. Segundo, em razão das circunstâncias sob as quais surgiu, a Economia do Desenvolvimento se sobrecarregou de esperanças e ambições irrealistas que logo teriam que ser afastadas.

De fato, grande parte das políticas econômicas implementadas durante a era de ouro do capitalismo foi suportada diretamente pelas teorias do desenvolvimento, mas também significativamente por uma "ideologia desenvolvimentista", que pode ser sintetizada na crença generalizada do desenvolvimento econômico (capitalista) como panacéia para os problemas da sociedade. E a ligação com o contexto da Guerra Fria é bem direta. Naquele momento essa ideologia foi necessária à manutenção da ordem sistêmica, na medida em que foi uma resposta às promessas que vinham do outro lado da "cortina de ferro".

No entanto, as promessas precisam ser minimamente cumpridas e ficou claro nos anos de 1960 que se o crescimento econômico vinha ocorrendo o mesmo não se podia dizer da distribuição dos seus frutos. ${ }^{8}$ Essa contradição expressouse intensamente a partir do momento em que o vigor do crescimento começou a se esgotar. ${ }^{9}$ Já nos anos de 1970 estabelece-se uma crise caracterizada pela combinação de baixas taxas de crescimento com altas taxas de inflação (fenômeno que ficou conhecido como estagflação).

Nesse contexto, as idéias neoliberais passam a ganhar terreno. Principalmente entre os países capitalistas desenvolvidos, comumente argumenta-se que as políticas nacionais fundamentadas em preceitos desenvolvimentistas não haviam logrado êxito na sua proposição basilar: a idéia de que o progresso material, sob o modo de produção capitalista, seria suficiente para contemplar, no mínimo, as necessidades básicas históricas da população do planeta. Ao contrário disso, assistia-se naquele momento a um acirramento das desigualdades sociais, além da inflexão no extraordinário crescimento econômico do pós-guerra, sem que as diferenças de desenvolvimento entre os países tivessem sido efetivamente diminuídas.

Esse processo se evidencia empiricamente. Como mostrado nas tabelas que seguem, o crescimento médio do PIB, considerando-se todos os países do mundo, sai de um patamar de 5,48\% no período $1961-1973$ para $3,24 \%$ no período subseqüente, e chega a atingir 2,51\% na década de 1990 . Para os dados relativos ao crescimento médio do PIB per capita, os resultados não são muito diferentes (passa de 3,41\% no período 1961-1973 para 1,40\% no período sub-

8 A referência à distribuição dos frutos não tem o mesmo sentido que distribuição de renda. Aqui estamos nos referindo à participação das economias no processo global de produção de riqueza, que aponta para diferenças significativas na distribuição internacional do trabalho. Esse é o foco da teoria crítica do desenvolvimento econômico, sobretudo as vertentes Neomarxista e Cepalina. Uma discussão a esse respeito pode ser encontrada em Hunt (1989).

9 Há estudos que mostram que as oportunidades de investimento foram se estreitando, evidenciando o esgotamento do padrão tecnológico em vigor. Susan Strange (1976) mostra esse movimento. Em Cano (1993) há uma contextualização histórica desses fenômenos ao que ele chama de passagem da II à III Revolução Industrial. A Escola Regulacionista (Lipietz 1988 \& Coriat 1985) trata esse período como sendo de mudança do regime e modo de regulação da acumulação de capital. 
seqüente). No entanto, como os países do Leste Asiático destoam dos demais no período em questão, e como nos países da América Latina e Caribe a crise ganha força apenas a partir da década de 1980 (quando o crescimento médio do PIB cai para 1,91\% e a média do PIB per capita apresenta uma queda de 0,11\%), esses dados são ainda piores para os países ricos da OCDE. Entre esses, o crescimento médio do PIB passa de 5,42\% para 2,90\%.

\section{TABELA 1 - CRESCIMENTO MÉDIO DO PIB EM REGIÕES E PAÍSES SELECIONADOS (EM \%)}

\begin{tabular}{ccccc}
\hline $\begin{array}{c}\text { REGIÕES PAÍSES/ } \\
\text { PERÍODOS }\end{array}$ & $1961-1973$ & $1974-1979$ & $1980-1989$ & $1990-2001$ \\
\hline Mundo & 5,48 & 3,24 & 3,02 & 2,51 \\
Alemanha & 4,51 & 2,39 & 1,97 & 1,74 \\
França & 5,41 & 2,83 & 2,38 & 1,93 \\
Reino Unido & 3,18 & 1,48 & 2,40 & 2,18 \\
Estados Unidos & 4,11 & 3,04 & 3,00 & 2,90 \\
Países ricos & 5,42 & 2,90 & 2,92 & 2,32 \\
da OCDE & & & & 7,39 \\
Leste Asiático & 5,31 & 6,48 & 7,39 & \\
e Pacífico & & & & \\
América Latina & 5,79 & 5,05 & & \\
e Caribe & & & & \\
\hline
\end{tabular}

FONTE: Banco Mundial (2003), World Development Indicators

NOTAS: 1) Inclui os seguintes países: Samoa Americana, Camboja, China, Fiji, Indonésia, Kiribati, Rep. Dem. Coréia, Lao PDR, Malásia, Ilhas Marshall, Micronésia, Mongólia, Myanma, Palau, Papua-Nova Guiné, Filipinas, Samoa, Ilhas Salomão, Tailândia, Timor-Leste, Tonga, Vanuatu, Vietnã.

TABELA 2 - CRESCIMENTO MÉDIO DO PIB PER CAPITA EM REGIÕES E PAÍSES SELECIONADOS (EM \%)

\begin{tabular}{ccccc}
\hline Regiões países/ períodos & $1961-1973$ & $1974-1979$ & $1980-1989$ & $1990-2001$ \\
\hline Mundo & 3,41 & 1,40 & 1,28 & 1,06 \\
Alemanha & 4,12 & 2,58 & 1,88 & 1,36 \\
França & 4,35 & 2,34 & 1,85 & 1,53 \\
Reino Unido & 2,62 & 1,47 & 2,20 & 1,97 \\
Estados Unidos & 2,84 & 2,01 & 2,05 & 1,66 \\
Países ricos da OCDE & 4,34 & 2,12 & 2,30 & 1,63 \\
Leste Asiático e Pacífico & 2,96 & 4,63 & 5,69 & 6,07 \\
América Latina e Caribe & 3,05 & 2,59 & $-0,11$ & 1,10 \\
\hline
\end{tabular}

FONTE: Banco Mundial (2003), World Development Indicators.

De acordo com o argumento neoliberal, as raízes dessa crise

(...) estavam localizadas no poder excessivo e nefasto dos sindicatos e, de maneira geral, no movimento operário, que havia corroído as bases da acumulação capitalista com suas pressões reivindicativas sobre os salários e com sua pressão parasitária para que o Estado aumentasse cada vez mais os gastos sociais. (Anderson 1995:10) 
O remédio seria, então, romper com essas tendências. E é nesse sentido que, diferente do liberalismo clássico ${ }^{10}$, o neoliberalismo irá pregar um "Estado forte" para garantir o "Estado mínimo", visto que ao mesmo caberia o papel de garantir o livre funcionamento do mercado através da implementação de reformas estruturais de desmantelamento do Estado de Bem-Estar.

Esse programa não impôs, no entanto, sua hegemonia do dia para a noite. Os primeiros países a implementá-lo foram, sem dúvida, os latino-americanos. ${ }^{11}$ Todavia levou aproximadamente uma década até que as eleições, em 1979, de Margareth Thatcher no Reino Unido e, em 1980, a de Ronald Reagan nos Estados Unidos marcassem, de forma inconteste, a ascensão neoliberal, com sua expansão do plano teórico-ideológico para o político. Esses foram os primeiros países capitalistas avançados declaradamente empenhados em pôr em prática o programa neoliberal. ${ }^{12}$

A década de 1980 foi, então, caracterizada pela expansão do neoliberalismo para grande parte dos países capitalistas avançados: "No início, somente governos explicitamente de direita radical se atreveram a pôr em prática políticas neoliberais; depois, qualquer governo, inclusive os que se autoproclamavam e se acreditavam de esquerda, podia rivalizar com eles em zelo neoliberal" (Anderson 1995:14).

E a dèbacle do mundo socialista, emblematizada pela queda do Muro de Berlim no ano de 1989, representa, nesse sentido, um marco histórico importante. Como destaca Ianni (1999:109):

(...) com a dissolução do bloco soviético, intensifica-se e estende-se o desenvolvimento do capitalismo. As nações que haviam experimentado projetos socialistas transformamse em espaços do mercado mundial, no qual predominam as empresas, corporações e conglomerados transnacionais.

Esse não foi, no entanto, o triunfo de qualquer capitalismo, mas sim daquele específico liderado por Reagan e Thatcher. Apesar de já serem evidentes no final dos anos de 1980 e início dos 1990 os limites do neoliberalismo nos países ocidentais, assiste-se à sua expansão para os países do Leste Europeu; e como bem nota Anderson (1995:18), "não há neoliberais mais intransigentes no mundo do que os 'reformadores' do Leste".

10 Esta não é, certamente, a única diferença entre o liberalismo clássico e o neoliberalismo. Não cabe aqui, no entanto, uma revisão de todas elas. Uma análise detalhada sobre o assunto pode ser vista em Carcanholo (2004).

11 Ao falar sobre o caso latino-americano, e mais especificamente sobre o emblemático caso chileno, destaca Anderson (1995:19): “(...) genealogicamente este continente foi testemunha da primeira experiência neoliberal sistemática do mundo. Refiro-me, bem entendido, ao Chile sob a ditadura de Pinochet. Aquele regime tem a honra de ter sido o verdadeiro pioneiro do ciclo neoliberal da história contemporânea."

12 As experiências inglesa e norte-americana de implementação do neoliberalismo foram, no entanto, bastante distintas. Como destaca Anderson (1995, p. 12): "O modelo inglês foi, ao mesmo tempo, o pioneiro e o mais puro. (...) A variante norte-americana era bem distinta. Nos Estados Unidos, onde quase não existia um Estado de Bem-Estar do tipo europeu, a prioridade neoliberal era mais a competição militar com a União Soviética, concebida como uma estratégia para quebrar a economia soviética e, por esta via, derrubar o regime comunista na Rússia.” 
Nos termos apresentados na presente seção, ou seja, em termos políticos e ideológicos,

[:] o neoliberalismo alcançou êxito num grau com o qual seus fundadores provavelmente jamais sonharam, disseminando a simples idéia de que não há alternativas para os seus princípios, que todos, seja confessando ou negando, têm de adaptar-se a suas normas. Provavelmente nenhuma sabedoria convencional conseguiu um predomínio tão abrangente desde o início do século como o neoliberal hoje. (Anderson 1995:18)

Por outro lado, com a dèbacle do mundo socialista consolida-se "um novo ciclo de expansão do capitalismo, como modo de produção e processo civilizatório de alcance mundial" (Ianni 1997:7). A esse processo convencionou-se chamar globalização - talvez um dos fenômenos mais citados ao longo da última década do século XX, e que por esse motivo se mostra de tão difícil trato. Nas palavras do sociólogo polonês Zygmunt Bauman (1999:7):

A "globalização" está na ordem do dia; uma palavra da moda que se transforma rapi-
damente em um lema, uma encantação mágica, uma senha capaz de abrir as portas de
todos os mistérios presentes e futuros. Para alguns, "globalização" é o que devemos fazer
se quisermos ser felizes; para outros, é a causa da nossa infelicidade. Para todos, porém,
"globalização" é o destino irremediável do mundo, um processo irreversível; é também
um processo que nos afeta a todos na mesma medida e da mesma maneira. Estamos
todos sendo "globalizados" - e isso significa basicamente o mesmo para todos.

Não cabe aqui, obviamente, entrar nos pormenores de todo um debate que gira em torno da idéia de globalização, tema demasiado amplo e complexo para os propósitos do presente artigo. Contudo, é preciso destacar alguns pontos relacionados a esse processo e suas teorizações para que possamos reunir elementos suficientes à compreensão do surgimento de uma Nova Economia do Desenvolvimento.

O primeiro deles diz respeito ao declínio do Estado-nação enquanto instituição de coordenação e liderança das decisões estratégicas de desenvolvimento, resultado do próprio processo do desenvolvimento capitalista. Esse elemento aparece como um fenômeno imposto, inexorável e irreversível (e não como resultado da conjunção de opções político-ideológicas). A globalização traria consigo o "declínio" necessário do Estado-nação.

O fato é que a reforma do Estado foi defendida, difundida e orquestrada pelos principais organismos multilaterais - entre esses se destacam o Fundo Monetário Internacional (FMI), o Banco Mundial (BIRD) e a Organização Mundial do Comércio (OMC) -, tornando-se a palavra de ordem predominante em todo o mundo após o fim da Guerra Fria. (Ianni 1999:109-10)

Isso traz à luz um segundo ponto importante relacionado ao processo de globalização: de uma forma geral, redefine-se e intensifica-se o papel e o poder dos organismos multilaterais em ditar agendas globais, ou seja, em ditar "boas" normas e condutas que deveriam ser seguidas por "todos" os países do mundo. 
O Consenso de Washington pode ser considerado, dessa forma, a primeira expressão da tendência à construção dessas agendas supostamente global. E com o poder crescente obtido pelos organismos multilaterais, "o Estadonação começa a ser obrigado a compartilhar ou aceitar decisões e diretrizes provenientes de centros de poder regionais e mundiais" (Ianni 1997:13).

Um último ponto diz respeito à consolidação de blocos regionais, com graus de organização e institucionalidade heterogêneos, porém todos sintonizados com a idéia de que o espaço supranacional é o nível relevante de discussão e convergência de políticas de desenvolvimento.

Também a edificação dos blocos regionais de poder é utilizada como um argumento contra os Estados nacionais. No entanto, até mesmo no que diz respeito à formação dos blocos regionais, o Estado nacional não pode deixar de ser uma referência importante. Como destaca Ianni (1997:14), a chamada regionalização "pode ser vista como uma necessidade da globalização, ainda que seja simultaneamente um movimento de integração de estados-nações”.

É verdade que existe, sob o modo de produção capitalista, uma tendência histórica à superação progressiva das fronteiras nacionais no marco do mercado mundial. No entanto, destaca Wood (2003:8), se

(...) o capital foi capaz de estender seu alcance econômico para muito além das fronteiras de qualquer nação-Estado, (...) o capitalismo está longe de prescindir da naçãoEstado. O capital precisa do Estado para manter a ordem e garantir as condições de acumulação, e, independentemente do que tenham a dizer os comentadores a respeito do declínio da nação-Estado, não há evidência de que o capital global tenha encontrado um instrumento mais eficaz.

Em síntese, o ponto a destacar é que esses fenômenos ("ocaso" do Estado Nacional, consolidação do espaço supranacional e das agendas "globais") são, em grande medida, responsáveis por escamotear a existência de diferenças e hierarquias globais (Ianni 1997:8):

De maneira lenta e imperceptível, ou de repente, desaparecem as fronteiras entre os três mundos, modificam-se os significados das noções de países centrais e periféricos, do norte e sul, industrializados e agrários, modernos e arcaicos, ocidentais e orientais.

Além disso, diferentemente do que os Estados Unidos representaram no período posterior à Segunda Guerra para as nações "não alinhadas" (ou seja, as nações fora do campo soviético), parece haver no período recente uma perda generalizada de referência, apesar do grande poder ainda exercido pelos norte-americanos (Bauman 1999:66) ${ }^{13}$ :

13 Apesar de estar em discussão o destino da hegemonia norte-americana, é fato notável que essa nação continua falando "em nome da humanidade como um todo". Um exemplo recente disso é a chamada "guerra contra o terrorismo". No discurso oficial não se trata meramente de defender os interesses norte-americanos, são interesses da "comunidade internacional". 
(...) ninguém parece estar no controle agora. Pior ainda - não está claro o que seria, nas circunstâncias atuais, "ter o controle". (...) não há mais uma localidade com arrogância bastante para falar em nome da humanidade como um todo ou para ser ouvida e obedecida pela humanidade ao se pronunciar. Nem há uma questão única que possa captar e teleguiar a totalidade dos assuntos mundiais e impor a concordância global.

E se não há, como ressalta Bauman, uma questão única que possa captar e teleguiar a totalidade dos assuntos mundiais, passa a existir, em contrapartida, uma série de questões, discutidas no âmbito supranacional e implementadas no âmbito subnacional, de tal forma que o nacional é posto em segundo plano, deixando de ser considerado o âmbito relevante de discussão e implementação de estratégias de desenvolvimento.

Conforme se pretende argumentar na próxima seção, o consenso sobre o "ocaso" do Estado Nacional, a força adquirida pelos organismos multilaterais e suas agendas globais (e o conseqüente escamoteamento das hierarquias em nível global) e a idéia de que o âmbito supranacional deve ser a esfera de poder relevante aparecem claramente nos novos debates sobre desenvolvimento. Em contraste com a velha Economia do Desenvolvimento (calcada no Estado Nacional e na diferença entre eles), muda-se o foco para temáticas que devem ser discutidas em âmbito global e seguidas por todos os países, independente da sua posição na hierarquia internacional.

Hirschman, em consonância com o argumento aqui defendido, oferece uma pista dos novos caminhos trilhados pela Economia do Desenvolvimento (Hirschman 1982:22):

Da mesma forma que o conceito do "típico país subdesenvolvido" rompeu-se em diversas categorias de países, cada um com características próprias, assim a anteriormente básica orientação da Economia do Desenvolvimento (a renda per capita) dissolveu-se em uma variedade de objetivos parciais, cada qual requerendo consulta a diferentes especialistas.

Como se pretende destacar mais adiante, a discussão sobre desenvolvimento local e territorial seria uma dessas "especialidades", e sua projeção é em grande medida fruto desses impasses das velhas teorias do desenvolvimento.

\section{A nova Economia do Desenvolvimento}

Conforme se procurou mostrar ao longo da seção anterior, a partir da década de 1970, a economia mundial passa por profundas transformações. A ascensão da ideologia neoliberal, as mudanças na estrutura produtiva e nas relações de produção, o aprofundamento do processo de globalização e a criação de novos espaços figuram, segundo a perspectiva aqui adotada, entre as marcas fundamentais da história recente do capitalismo mundial. 
Como não poderia deixar de ser, esses fatores terão influência decisiva sobre os rumos da teoria econômica. O que se assiste no bojo dessas transformações é a retomada da hegemonia neoclássica, perdida no contexto da crise dos anos de 1930, e uma diminuição do espaço adquirido pelas teorias de inspiração keynesiana nesse mesmo contexto. No que diz respeito especificamente ao objeto do presente estudo, esse período de crise marca de forma inconteste o declínio da Economia do Desenvolvimento.

De uma forma geral, pode-se dizer que o debate sobre desenvolvimento econômico, no sentido carregado pelas teorias do pós-guerra, adquire, a partir da década de 1980, papel secundário no debate mundial. Isso se deve, em parte, à constatação de que o desenvolvimento econômico, conforme defendido até então, não havia promovido uma melhor distribuição de renda e uma diminuição nas desigualdades espaciais (não por acaso nesse mesmo período proliferam os estudos sobre desigualdade de renda e pobreza). Se antes as preocupações estavam voltadas para a desigualdade entre os países, a partir desse momento as atenções se voltam para essas outras duas formas de desigualdade (individual e espacial). Além disso, eram evidentes os danos ambientais da intensa produção industrial do período anterior. Especificamente nesse caso, os debates sobre meio ambiente, que ganham crescente relevo, passam a ocorrer com base na polarização desenvolvimento econômico versus preocupação ambiental. Essas seriam as novas temáticas incorporadas ao debate sobre desenvolvimento, que aparecem tanto no pensamento heterodoxo quanto nas vertentes mais ortodoxas.

A partir desse momento, o debate mais universalizante sobre desenvolvimento cede lugar a um sem-número de debates paralelos, cada um deles voltado para um dos aspectos mencionados acima. Essa seria uma mudança significativa no debate, caracterizado agora por seu caráter difuso, fragmentado, com o desenvolvimento sendo discutido em seus vários aspectos, em suas múltiplas dimensões.

A redefinição da temática do desenvolvimento econômico não ocorreu, como é natural, abruptamente. Numa primeira etapa, ainda nos anos de 1960, à medida que os processos de industrialização de transição ao capitalismo avançado iam ocorrendo, houve evidências bastante claras de que as condições de desigualdade na distribuição da riqueza global não seriam superadas.

Diana Hunt (1989:71), na discussão que faz a respeito da redefinição da temática do desenvolvimento econômico, explora essa fase em que as evidências de que o desenvolvimento capitalista não havia cumprido suas promessas eram fortes. Segundo ela, no final dos anos de 1960 e começo dos anos de 1970, as análises neomarxistas ${ }^{14}$ enfatizaram a perpetuação da pobreza no Terceiro

14 A denominação das Escolas do Pensamento é certamente arbitrária, e comumente não conta com a concordância dos participantes de cada uma delas. Esse é precisamente o caso da referência aos neomarxistas. Essa referência é feita para caracterizar um grupo de autores de formação e perspectiva marxista que se propuseram a investigar temas que não são aceitos pelo marxismo ortodoxo. Um desses temas é o subdesenvolvimento. Os representantes mais conhecidos são Paul Baran, Gunder Frank, Theotônio dos Santos e Rui Mauro Marini. 
Mundo e ganharam repercussão acadêmica. Além dessas análises, outras enfatizaram a permanência da concentração da riqueza global em alguns países. As discussões sobre esses temas alcançaram diversos fóruns, incluindo instituições acadêmicas e certos órgãos da ONU, sobretudo o International Labour Organization (ILO) ${ }^{15}$.

Por outro lado, para além da redefinição da temática do desenvolvimento, conforme indica Diana Hunt, há uma requalificação que poderia ser identificada como uma mudança de objeto, denotando uma mudança mais profunda de concepção. Dois movimentos nesse sentido são relevantes: o primeiro diz respeito a um avanço de movimentos preservacionistas de natureza ecológica, e o segundo de desenvolvimento sustentável, que de certa forma significa uma incorporação das preocupações dos ecologistas na perspectiva do desenvolvimento econômico.

Segundo Layrargues (1997), o conceito de ecodesenvolvimento, isto é, do desenvolvimento com preservação da natureza, foi originalmente formulado por Maurice Strong em 1973. Ele consiste na definição de um estilo de desenvolvimento adaptado às áreas rurais do Terceiro Mundo, baseado na utilização criteriosa dos recursos locais, sem comprometer o esgotamento da natureza. Nos anos de 1980, Ignacy Sachs apropria-se do conceito, aprimorando a sua definição, criando um quadro de estratégias para o ecodesenvolvimento. Esse modelo baseia-se em três pilares: eficiência econômica, justiça social e prudência ecológica.

O principal aspecto diferenciador do ecodesenvolvimento em relação a outras formas de desenvolvimento, para além do seu foco na preservação ambiental, é o alongamento do prazo do planejamento e, portanto, do horizonte de cálculo dos efeitos das decisões presentes. Entende-se que a satisfação das necessidades das gerações futuras deve ser garantida, isto é, deve haver uma solidariedade diacrônica (relativa à evolução temporal), sem comprometer a solidariedade sincrônica (que ocorre ao mesmo tempo) com a geração presente, já por demais sacrificada pelas disparidades sociais.

Já o desenvolvimento sustentável tem origem nas ações da ONU. Em 1983, a Assembléia Geral da ONU criou a Comissão Mundial sobre Meio Ambiente e Desenvolvimento, e o primeiro relatório da comissão, intitulado Nosso Futuro Comum, tinha como objetivo a proposição de estratégias ambientais de longo prazo para se obter um desenvolvimento sustentável por volta do ano 2000. De acordo com essa perspectiva, a questão ambiental deve ser encarada como uma preocupação da humanidade, que demandaria esforços de todos os países, independente da responsabilidade histórica de cada um deles na degradação ambiental. 
Apesar das semelhanças existentes entre os conceitos de ecodesenvolvimento e desenvolvimento sustentável, há diferenças importantes que devem ser consideradas. Em primeiro lugar, enquanto a concepção do ecodesenvolvimento trilha o caminho crítico de contestação da forma do desenvolvimento capitalista, postulando uma reorientação das razões de mercado, propondo uma limitação dos padrões de consumo dos países mais avançados em favor dos países mais pobres, a concepção de desenvolvimento sustentável evita abordar a origem das condições atuais, sustentando que as inovações tecnológicas certamente permitirão o acesso de todos os povos à fartura, sem comprometimento da sustentabilidade ambiental.

A conclusão mais plausível dessa comparação entre os dois conceitos é que o desenvolvimento sustentável, sob a pressão da nova realidade ecológica e da necessidade de assumir uma nova postura, desponta sob uma nova roupagem, sem que tenha sido necessário modificar sua estrutura de funcionamento. $\mathrm{O}$ mecanismo cujo funcionamento é dependente da lógica de mercado sequer foi abalado, ou melhor, saiu até mais fortalecido. O desenvolvimento sustentável assume claramente a postura de um projeto ecológico neoliberal.

Os melhores exemplos da incorporação dessas temáticas no pensamento convencional são, indubitavelmente, as bases teóricas das proposições de políticas dos organismos multilaterais, como o Banco Mundial ${ }^{16}$ ou o FMI $^{17}$, e os chamados modelos de crescimento endógeno, que incorporaram nas suas funções de produção variáveis como capital humano, capital social e até mesmo capital natural. ${ }^{18}$

No campo mais heterodoxo, no entanto, esse mapeamento se torna ainda mais difícil. São inúmeras as perspectivas que trabalham com essas temáticas. O exemplo mais ilustrativo nesse caso talvez seja a própria CEPAL, que passa a dar mais ênfase à questão da eqüidade e sustentabilidade (não por acaso, a publicação do documento Transformação Produtiva com Eqüidade irá marcar o pensamento da CEPAL dos anos de 1990). Mesmo no caso de autores como Chang (2004), que, partindo de uma crítica às "boas políticas" prescritas pelo chamado Consenso de Washington, resgatam a velha noção de desenvolvimento (associada à industrialização), é patente a incorporação de novos critérios para definir desenvolvimento.

\footnotetext{
16 A ênfase dada à questão da desigualdade de renda e pobreza por essa instituição aparece repetidamente no seu documento de maior repercussão: World Development Report. O WDR de 1990, intitulado Poverty, o de 2000/2001 (Attacking Poverty) e 2006 (Equity and Development) possuem claramente esse viés. O foco na questão ambiental aparece um pouco mais recentemente. O WDR de 2003, intitulado Sustainable Development in a Dynamic World, pode ser citado como exemplo da incorporação da temática ambiental pela instituição.

17 Nesse sentido, é significativo o fato de o FMI ter incorporado recentemente no rol de condicionalidades, impostas às nações "assistidas", cláusulas "sociais".

18 Esta que ficou conhecida como Nova Teoria do Crescimento Endógeno foi inaugurada pelos novos clássicos Lucas e Romer que, por volta de 1985, rompem com a teoria tradicional do crescimento - na qual o modelo de Solow é o mais representativo. O ponto central da ruptura entre a velha teoria e a nova teoria está no relaxamento do axioma de rendimentos constantes. A taxa de crescimento passou a depender basicamente do estoque de três fatores: capital físico, capital humano e conhecimento (ou progresso técnico), que podem ser objeto de acumulação e, ademais, geram externalidades (De Mattos 1998:23-4).
} 
Nesse sentido, apesar das teorias aqui indicadas apresentarem diferenças importantes que não permitem tratá-las como um corpo teórico homogêneo, pode-se dizer que todas elas compartilham um mesmo ideal de desenvolvimento: não mais aquele "desenvolvimento econômico" do período anterior, medido somente em termos da produção nacional (preferencialmente a produção per capita, incapaz de mostrar a existência de disparidades de renda) ${ }^{19}$ e que tinha como meta diminuir as disparidades de renda entre as nações, mas um desenvolvimento que é "sustentável" em sentido amplo, ou seja, um desenvolvimento baseado em uma sustentabilidade "física" (ecológica), "econômica" (de durabilidade ao longo do tempo) e "social" (inclusiva).

Chamaremos de Nova Economia do Desenvolvimento esse conjunto de dimensões, com as suas respectivas teorias, não só por acreditar que elas guardam relação entre si (compartilhando um mesmo ideal de desenvolvimento), mas também por crer que guardam relação com a Economia do Desenvolvimento do pós-guerra (pois, apesar da incorporação de novas temáticas, o foco da disciplina continua sendo o desenvolvimento).

Dessas dimensões, no entanto, dedica-se especial atenção ao desenvolvimento local e ao desenvolvimento territorial não só pela repercussão que tiveram nos anos de 1990 e nos anos 2000, mas também pelo conteúdo ideológico carregado por essas perspectivas. Isso porque, se considerarmos que a natureza da Política do Desenvolvimento Econômico do período do pós-guerra confundia-se com uma determinada forma do Estado capitalista, será possível admitir que um primeiro nível de transformação a ser determinado pela concepção neoliberal está relacionado ao tipo de intervenção apropriado a um mundo em que a regulação das decisões está dada predominantemente pelo mercado. Para tanto, era preciso mostrar queo desenvolvimento não exigia uma presença significativa do Estado, este pensado em nível nacional. ${ }^{20}$ Todavia, isso se deu ao tempo em que houve uma revitalização do território, porém numa escala subnacional, como será visto na próxima seção.

\subsection{Desenvolvimento territorial na Nova Economia do Desenvolvimento}

Antes de iniciar precisamente com a análise do papel desempenhado pelo aporte do desenvolvimento territorial nos debates sobre desenvolvimento econômico, vale lembrar que a preocupação com a dimensão espacial do desenvolvimento econômico não data de tempos recentes. É possível encontrar algumas referências, ainda que esparsas, entre os autores clássicos e em Marx.

19 A centralidade dessa unidade de medida é freqüentemente reiterada pelos teóricos do desenvolvimento. Como afirma Lewis (1984:77): "A economia do desenvolvimento lida com a estrutura e o comportamento das economias nas quais a produção per capita é inferior a 2 mil dólares (dólares dos Estados Unidos, de 1980).”

20 Se tomarmos a referência do Brasil, fica bastante claro que o Estado que se discute no âmbito da teoria do desenvolvimento é aquele que se identificaria ao âmbito da União, isto é, à esfera Federal. As demais esferas estadual e municipal - certamente cumprem funções complementares, mas têm uma lógica mais fortemente ligada aos "serviços públicos" e menos à coordenação/liderança do desenvolvimento capitalista. 
Mas, a despeito das inúmeras formulações e dos avanços teóricos, a questão regional ficou durante muito tempo relegada ao segundo plano. Como, "nos anos 50 e 6o, o debate sobre o desenvolvimento regional e urbano recebeu influência direta de todas as correntes principais das chamadas teorias do desenvolvimento econômico (...), ocorre uma transposição muitas vezes direta do debate internacional e nacional para a escala regional" (Brandão 2003:33). Sobre o âmbito mais concreto da política econômica, destaca-se que "a preocupação com a política regional ficou muito atrás de outros aspectos da intervenção governamental mesmo depois que muitos economistas perdessem sua fé radical na economia de mercado". (Richardson 1975:17)

Nesse período de auge da Economia do Desenvolvimento, a ênfase recaía sobre o âmbito nacional; pensava-se muito mais em como dissipar as desigualdades nessa esfera. Além disso, note-se que em todos os casos a política regional foi pensada "de cima para baixo", ou seja, como um processo que emana do Estado. Com a crise do desenvolvimentismo e a ascensão do neoliberalismo, observa-se o declínio desse tipo de política, e conseqüentemente o declínio da "região" como lócus de atuação política. ${ }^{21}$ Nos termos de Vainer (2002), é nesse período que os estudiosos do tema começam a questionar qual a escala de ação política pertinente ou prioritária, seja para a análise econômica e social, seja para a ação política eficaz.

Ocorre, no entanto, um fenômeno, relativamente recente, de revalorização do espaço na economia. Como ressalta Vainer (2002:14):

Não seria exagero dizer que o debate intelectual e político se vem realizando sob o signo de categorias que remetem às escalas espaciais: globalização, blocos regionais, desenvolvimento local, dissolução das fronteiras nacionais, identidades locais, entre outras, são expressões que freqüentam com igual intensidade tanto os trabalhos e encontros acadêmicos quanto os meios de comunicação de massa e o debate político.

No que se refere aos estudos sobre as desigualdades espaciais e sobre os meios de promover o desenvolvimento desses espaços, destaca-se o surgimento do território e do desenvolvimento territorial. Segundo Shneider (2004:102), "é neste contexto que ganha relevo o território, agora como uma noção com estatuto operacional que permite a superação dos condicionantes e limites do aporte regional”. Conforme será destacado mais adiante, também nesse mesmo período, assiste-se ao surgimento do local - e, conseqüentemente, do desenvolvimento local. No entanto, apesar de estarem ligados a correntes teóricas não muito distintas, essas noções não só apresentarão conteúdos diferentes, como também irão se desdobrar em práticas políticas diferentes.

21 "O desgaste da noção de região e, mais precisamente, de desenvolvimento ou planejamento regional, iniciase com a crise da capacidade de intervenção macroeconômica e macrossocial do Estado, que ocorre a partir de meados da década de 1970 e se agudiza na década seguinte, especialmente com a influência crescente do ideário neoliberal sobre as perspectivas keynesianas que vigoravam desde o final da Segunda Guerra Mundial." (Shneider 2004:100) 
De fato, um dos aspectos que a revitalização do território na ciência econômica traz à tona é o das escalas de ação política. A elas são associados níveis teóricos, de maneira que a escala pertinente ou prioritária, seja para a análise econômica e social, seja para a ação política eficaz, passa a ser uma questão relevante. Atualmente esse debate, ao contrário do período anterior (quando a ênfase era posta no regional e no nacional), tem-se estruturado sobre as oposições entre o local e o global. Portanto, o que se assiste é o domínio tanto da escala local quanto da escala global, com subordinação teórica e política da escala nacional, em cujo âmbito está muito bem definido o papel do Estado em garantir a estabilidade, ou em dar as bases para o funcionamento regulador do mercado. (Vainer 2002:14)

De acordo com essa perspectiva, o local adquiriu uma importância estratégica para se alcançar o desenvolvimento nacional. Os governos locais (escala subnacional) estariam em condições de atrair empresas e promover sua competitividade. Ou seja, os governos locais gozam de "(...) muita flexibilidade, adaptabilidade e capacidade de manobra em um mundo de fluxos entrelaçados, demandas e ofertas cambiantes e sistemas tecnológicos descentralizados e interativos". Além disso, eles oferecem base histórico-cultural para a integração dos indivíduos. Ou seja, os governos locais gozam de uma "maior capacidade de representação e legitimidade com relação a seus representados; são agentes institucionais de integração social e cultural de comunidades territoriais" (Borja \& Castells apud Vainer 2002:17).

Ese por um lado os governos locais adquiriram importância estratégica, por outro, de acordo com essa perspectiva, os Estados nacionais se tornaram duplamente frágeis. São ao mesmo tempo

(...) demasiadamente pequenos para controlar e dirigir os fluxos globais de poder, riqueza e tecnologia, e demasiadamente grandes para representar a pluralidade de interesses sociais e identidades culturais da sociedade, perdendo legitimidade tanto enquanto instituições representativas como enquanto organizações eficientes (Borja \& Castells apud Vainer 2002: 17, grifos nossos).

Vale notar que uma perspectiva como essa, chamada aqui de localista, pode ser encontrada em diversos autores e correntes, não sendo possível oferecer um mapeamento preciso de sua extensão. No entanto, mesmo não constituindo um corpo teórico homogêneo, é possível afirmar que “(...) a rejeição da escala nacional e do Estado nacional como campo e ator predominantes da ação política está presente em todos os adeptos dessa perspectiva” (Vainer 2002:20). O lema é "engajar as cidades e os lugares na competição global" (Borja \& Castells apud Vainer 2002: 17, grifos nossos, p. 16). E essa noção, hoje hegemônica, é defendida e difundida sistematicamente pelos organismos multilaterais e agências globais.

Assim como sustenta a ideologia neoliberal, grande parte das teorias que utilizam o enfoque do desenvolvimento local apreende a globalização como algo inexorável e irreversível, que tendencialmente romperia os limites do 
controle dos Estados nacionais, estruturalmente fragilizados. Assim como os teóricos da globalização (globalistas), muitos teóricos do desenvolvimento local (localistas) consideram que com o processo de globalização o Estado perdeu força e deixou, portanto, de ser uma esfera de poder prioritária. É nesse sentido que para essas abordagens a política de desenvolvimento não pode ser mais produto tipicamente de uma ação pública de Estado, mas resultado da convergência de ações de múltiplos atores, alguns deles atuando nos âmbitos privado ou supranacional.

Vale realçar que poucos são os que questionam a existência de um processo de globalização (ou mundialização), embora exista uma série de divergências nas interpretações sobre a natureza e sentido desse processo. Exemplo: enquanto de acordo com a perspectiva globalista assiste-se à progressiva unificação do espaço global, causa e conseqüência do desmantelamento dos Estados nacionais, para outros "a globalização não é uma homogeneização, mas, ao contrário, é a extensão de um pequeno grupo de nações dominantes sobre o conjunto das praças financeiras nacionais" (Bourdieu 1998:54).

Além disso, há dissenso quando se trata da necessidade histórica do processo de globalização como avanço civilizatório e elemento dinâmico da produção global. Destacam-se como mais numerosos os que acreditam na inevitabilidade e irreversibilidade da globalização, assumindo que as suas causas seriam também inevitáveis e irreversíveis. Em contraponto, estão os que defendem que “a 'globalização' não é [seja] uma nova fase do capitalismo, mas uma retórica 'invocada' pelos governos para justificar sua submissão voluntária aos mercados financeiros" (Bourdieu \& Wacquant 2000).

Em resumo: os globalistas e localistas estariam então no primeiro grupo, o dos que acreditam na unificação do espaço global e na sua necessidade histórica. E apesar das inúmeras posturas analíticas e projetos políticos reconhecíveis no campo dos globalistas, um ponto de convergência é o reconhecimento, conformado ou entusiasta, de que o Estado Nacional é cada vez mais impotente para fazer frente aos desafios colocados pelas realidades políticas, econômicas, sociais, culturais e ambientais. Esse é também um ponto de convergência com o localismo. (Vainer 2002:16)

No caso do desenvolvimento territorial, ao contrário, ainda se considera o Estado parte importante do processo. Como destaca Shneider (2004:102):

(...) o território emerge como nova unidade de referência para a atuação do Estado e a regulação das políticas públicas. Trata-se, na verdade, de uma tentativa de resposta do Estado, entendido como instituição jurídico-social, às fortes críticas a que vinha sendo submetido, sobretudo tendo em vista a ineficácia e a ineficiência de suas ações, seu alto custo para a sociedade e a permanência das mazelas sociais mais graves como a pobreza, o desemprego, a violência, etc.

Esses não são, no entanto, os que reivindicam, no debate sobre as escalas de ação política, a centralidade da escala nacional (chamados de neonacionalistas). De acordo com a perspectiva neonacionalista (Vainer 2002:21): 
(...) ao escamotearem a escala nacional, globalistas e localistas de todos os tipos estariam fazendo o jogo da própria globalização, cujo ponto de ataque central, não por acaso, é o Estado nacional, única escala e instituição escalar em condições de viabilizar, suscitar, a construção de alternativas viáveis ao capitalismo simultaneamente globalitário e fragmentador.

Fugindo um pouco a essas perspectivas, conhecidas por adotarem uma postura uniescalar, a corrente do desenvolvimento territorial defende a combinação das múltiplas escalas - conformando o que se convencionou chamar de estratégia transescalar. Isso porque, ao mesmo tempo em que pode ser interessante uma atuação mais forte dos governos na promoção do desenvolvimento de suas localidades, qualquer projeto econômico restrito apenas ao âmbito local está fadado ao fracasso.

Nesse sentido, advogam esses autores a necessidade tanto de uma abordagem quanto de uma estratégia transescalar; ou seja, o tratamento transescalar é necessário tanto em termos analíticos (escalas de análise) quanto para a construção de estratégias, de sujeitos e projetos políticos. Como destaca Vainer (2002:25), "qualquer projeto (estratégia?) de transformação envolve, engaja e exige táticas em cada uma das escalas em que hoje se configuram os processos sociais, econômicos e políticos estratégicos".

O grande exemplo de desenvolvimento territorial nos dias atuais é oferecido pela União Européia. A idéia é unir o que se convencionou chamar de "desenvolvimento de baixo para cima" e "desenvolvimento de cima para baixo". Nesse sentido, no caso da União Européia, foram mantidos os termos ordenamento e desenvolvimento territorial:

(...) ordenamento seria algo "consentido, outorgado e redistribuitivo", enquanto o desenvolvimento seria "desejado, partilhado e produtor de riquezas". (...) se pretende cruzar, num mesmo espaço, uma política “descendente (ordenamento) com uma política ascendente (desenvolvimento)” (Veiga 2002:13).

\section{Considerações finais}

Voltamos à pergunta do título do artigo: há uma Nova Economia do Desenvolvimento? A resposta que procuramos construir nas três seções do artigo é que sim.

Conforme mostrado ao longo da primeira seção, emerge no pós-guerra uma disciplina no interior da ciência econômica conhecida como Economia do Desenvolvimento. E, apesar do grande número e da diversidade de teorias que compõem a disciplina, foi possível identificar algumas características comuns a todas elas. Primeiramente, é patente a existência de uma mesma visão de mundo compartilhada por toda a Economia do Desenvolvimento. Assim, de uma forma geral, é possível reconhecer em todos os teóricos do desenvolvimento a utilização das receitas do desenvolvimento das nações capitalistas pioneiras para propor saídas aos países subdesenvolvidos. Além 
disso, e mais importante, é possível perceber que todos os autores têm como referência centrar para a promoção do desenvolvimento o Estado Nacional.

No entanto, se por um lado o Desenvolvimento Econômico emergiu como uma temática de extremo sucesso no campo da economia, por outro, em um período relativamente curto de tempo, assiste-se ao seu declínio. No bojo da crise dos anos de 1970, ascensão da ideologia neoliberal e transformações na estrutura produtiva, a Economia do Desenvolvimento se depara com uma série de dilemas teóricos e práticos.

Como resultado desse processo, o tema do desenvolvimento se tornou certamente mais amplo no conjunto das suas questões do que havia sido nos anos de 1950, principalmente devido à incorporação de novas temáticas. Ao substantivo desenvolvimento é apensado inúmeros adjetivos, o que confere ao termo uma suposta multiplicidade. Essa fragmentação interna à disciplina deu origem, no entanto, a uma série de subtemáticas e delimitações de escala que tornaram o campo do desenvolvimento mais complexo e difícil de ser compreendido na sua dimensão global.

Embora não tenhamos a pretensão de cobrir o conjunto das teorias de desenvolvimento, aquelas indicadas são suficientes para configurar perspectivas que se situam no campo da disciplina Desenvolvimento Econômico, porém com qualificações, segmentações e posturas teóricas distintas daquelas originárias. Essas mudanças indicam-nos o caminho do abandono do qualificativo econômico, em favor de uma disciplina mais complexa e pretensamente abrangente que seria a do Desenvolvimento. Nesse sentido, a Nova Economia do Desenvolvimento manteria pouco da perspectiva da sua origem, segmentando-se e ampliando-se por novas dimensões.

Acredita-se, no entanto, que essa segmentação/ampliação, apesar de seu caráter aparentemente positivo, traz problemas de outra grandeza para o entendimento do fenômeno. Em primeiro lugar, como até mesmo Cardoso (1995:150) reconhece, com esse processo o desenvolvimento deixa de ter a força fundadora e unificadora que possuía nos anos de 1960.

Indo um pouco além, é possível perceber que essas novas concepções deslocam do eixo das preocupações a disparidade de níveis de desenvolvimento econômico entre os países (base da desilusão de Hirschman). No atual contexto de mudança ideológica do papel do Estado, num mundo integrado pelo mercado internacional unificado e pelo espaço diplomático supranacional da ONU, o tema desenvolvimento perde identidade com o espaço nacional. O foco das preocupações, diferentemente do período anterior, não é mais diminuir as disparidades no desenvolvimento das nações.

Em síntese, o ponto a destacar é que a incorporação dessas novas perspectivas no debate sobre desenvolvimento econômico por vezes embaçam a existência de uma hierarquia global. A constituição do espaço supranacional e a importância crescente assumida pelos Organismos Multilaterais e suas "agendas globais" para o desenvolvimento não eliminam a velha polarização Norte-Sul, a estratificação 
global, a diferença sistêmica (dissimulada agora pela noção de uma integração dos espaços globais).

E, nesse sentido, a perspectiva do desenvolvimento local/territorial é exemplar.

Um primeiro ponto digno de nota é que, em muitos casos, a idéia de local tem sido tomada como auto-explicativa. A definição do que é (ou o que deveria ser) o local raramente aparece. Assim, o local adquire uma série de significados e usos. ${ }^{22}$ Contudo, essas dificuldades teórico-conceituais não parecem preocupar os "homens práticos". A solução encontrada parece simples (além de bastante pragmática): o local é o "espaço escolhido pelos planejadores para intervir" (Vainer 2002:19).

O mesmo vale para o impreciso conceito de território. Segundo Veiga (2002:12), “as vantagens das palavras 'espaço’ e 'território’ são evidentes: não se restringem ao fenômeno 'local', 'regional', 'nacional' ou mesmo 'continental', podendo exprimir simultaneamente todas essas dimensões”. E se, por um lado,"parece estar havendo, de fato, uma revalorização da dimensão espacial da economia; (...) tudo indica que tal evolução está longe de permitir que se considere a expressão 'desenvolvimento territorial' como um conceito propriamente dito" (Veiga 2002:5).

Segundo entende-se aqui, se o território for considerado uma base geográfica do Estado, base sobre a qual o Estado exerce sua soberania, o território expressa uma condição de poder, de poder político de Estado. E nesse sentido, a idéia de desenvolvimento local/territorial não poderia ser dissociada da noção de Estado. Muitos defensores do desenvolvimento territorial, principalmente os que se filiam ao desenvolvimento local, ao contrário, costumam ignorar o fato de haver uma hierarquia de poder no âmbito nacional.

Como se viu, há uma corrente defensora do desenvolvimento territorial que considera o Estado como uma esfera relevante. Mas mesmo nesses casos em que o desenvolvimento das regiões aparece como uma política de Estado, persiste o desprezo em relação à disparidade de níveis de desenvolvimento econômico entre os países.

Esse debate pode se tornar ainda mais desalentador, ao se pensar que a nova ideologia vigente, o neoliberalismo, limita as possibilidades do Estado como ator do desenvolvimento - papel que passa a ser atribuído ao mercado, como fruto natural da dinâmica capitalista. Até que ponto não é esse discurso um mero recurso ideológico cujo fim é ocultar uma ordem internacional que necessita de países pobres e ricos - tanto quanto necessita de classes privilegiadas e despossuídas, aqueles que trabalham e os que se apropriam do trabalho de outros. Admitir essa outra possibilidade implica corrigir os termos em que se vem discutindo o desenvolvimento econômico, a começar pela própria conceituação do termo e pela correção das expectativas em relação a um desenvolvimento nos marcos do modo de produção capitalista.

22 No artigo de Gonzáles (1998), isso pode ser visto claramente. Nesse trabalho, o autor apresenta aproximadamente oito diferentes definições de desenvolvimento local. 


\section{Referências}

ANDERSON, Perry (1995). "Balanço do neoliberalismo.” In SADER, Emir \& GENTILI, Pablo (Org.). Pós-neoliberalismo: as políticas sociais e o estado democrático. Rio de Janeiro: Paz e Terra.

BANCO MUNDIAL (2003). World Development Indicators. Washington: BIRD/Banco Mundial. 1 CD-ROM.

BAUMAN, Zygmunt (1990). Globalização: as conseqüências humanas. Rio de Janeiro: Zahar.

BIELSCHOWSKY, Ricardo (1998). "Evolución de las Ideas de la CEPAL." Revista de la CEPAL, Santiago, n. extraordinário. URL [On line]: http://www.cepal.org/ publicaciones/Secretaria Ejecutiva/7/LCG2037PE/bielchow.htm. Acesso em: 03 de dezembro de 2004.

(1996). Pensamento econômico brasileiro: o ciclo ideológico do desenvolvimento. Rio de Janeiro: Contraponto.

BOURDIEU, Pierre (1998). Contrafogos: tática para enfrentar a invasão neoliberal. Rio de Janeiro: Jorge Zahar.

BOURDIEU, Pierre \& WACQUANT, Loïc (2000). “A Nova Bíblia do Tio Sam." Le Monde Diplomatique. URL [On line]: http://www.lainsignia.org/2001/marzo/int_023.htm. Acesso em: 17 de outubro de 2006.

BRANDÃO, Carlos Antônio (2003). A dimensão espacial do subdesenvolvimento: uma agenda para os estudos regionais e urbanos. $200 \mathrm{f}$. Tese (Livre-docência em Economia) - Instituto de Economia, Universidade Estadual de Campinas.

CANO, Wilson (1993). Reflexões sobre o Brasil e a Nova (Des)Ordem Internacional. Campinas: UNICAMP.

CARCANHOLO, Marcelo (2004). "Neoliberalismo e desenvolvimento em uma economia periférica.” In CHAVIER, C. L. (Org.). Desenvolvimento desigual. Uberlândia: Edufu.

CARDOSO, Fernando H. (1995). "Desenvolvimento: o mais político dos temas." Revista de Economia Política, 15(4): 148-155.

CHANG, H. (2002) Chutando a escada. São Paulo: UNESP.

CORIAT, B. (1985). El taller y el cronometro: ensayo sobre el taylorismo, el fordismo y la producción en masa. 2. ed. Mexico: Siglo Veintiuno. 204 p.

DE MATTOS, Carlos A. (1998). "Evolución de las teorías del crecimiento económico y crisis de la enseñanza urbano-regional." Cadernos IPPUR, Rio de Janeiro, 12(1).

DOS SANTOS, Theotônio (2000). A Teoria da Dependência: balanços e perspectivas. Rio de Janeiro: Civilização Brasileira.

FURTADO, Celso (1979). Formação econômica do Brasil. São Paulo: Nacional.

(1969). Teoria e politica do desenvolvimento econômico. São Paulo: Nacional.

GONZÁLES, Román Rodríguez (1998). "La escala local del desarrollo: definición y aspectos teóricos." Revista de Desenvolvimento Econômico, 1(1). URL [On line]: http://www.unifacs.br/cedre/revista.htm. Acesso em: 16 de maio de 2006.

GRIFFIN, K (1999). Alternative strategies for Economic Development. 2. ed. London: Macmillan Press. 
HETTNE, B (1990). Development Theory and the Three Worlds. London: Longman.

HIRSCHMAN, Albert (1961). A estratégia de desenvolvimento econômico. Rio de Janeiro: Fundo de Cultura.

(1982). "Ascensão e declínio da Economia do Desenvolvimento." Revista de Ciências Sociais, 25(1).

HUNT, D. (1989). Economic Theories of Development: an analysis of competing paradigms. London: Harvester.

IANNI, Octavio (1997). A Era do Globalismo. Rio de Janeiro: Civilização Brasileira.

(1999). “O Estado-nação na época da globalização.” Econômica, 1(1): 119-122.

JAMESON, K. P. \& WILBER, C. K. (1996). The Political Economy of Development and Underdevelopment. 6. ed. New York: MacGraw Hill.

JONES, H. G. (1979). Modernas teorias do crescimento econômico: uma introdução. São Paulo: Atlas.

KANTH, Rajani (Ed.) (1994). Paradigms in Economic Development: classic perspectives, critiques, and reflections. New York: M. E. Sharpe.

KAY, C. (1989). Latin American Theories of Development and Underdevelopment. London: Routledge.

LARRAIN, J. (1989). Theories of Development: capitalism, colonialism, and dependency. London: Blackwell.

LAYRARGUES, P. P. (1997). "Do ecodesenvolvimento ao desenvolvimento sustentável: evolução de um conceito?” Proposta, 25(71):5-10.

LEHMANN, D. (1990). Democracy and development in Latin América. Philadelphia: Temple University.

LESSA, Carlos (1983). Quinze anos de política econômica. São Paulo: Brasiliense.

LEWIS, A. (1969). "O desenvolvimento econômico com oferta ilimitada de mão-de-obra." In AGARWALA, A. N. \& SINGH, S. P. (Org.). A economia do subdesenvolvimento. Rio de Janeiro: Forense.

(1984). "The State of Development Theory." American Economic Review 74(1).

LIPIETZ, A. (1988). Miragens e milagres: problemas da industrialização no Terceiro Mundo. São Paulo: Nobel.

MANTEGA, Guido (1990). A economia política brasileira. Petrópolis: Vozes.

MARINI, Ruy Mauro (1992). América Latina: dependência e integração. São Paulo: Brasil Urgente.

MYRDAL, Gunnar (1965). Teoria econômica e regiões subdesenvolvidas. Rio de Janeiro: Saga.

NURKSE, Ragnar (1957). Problemas de formação de capital em países subdesenvolvidos. Rio de Janeiro: Civilização Brasileira.

PREBISCH, Raúl (2000). "O desenvolvimento econômico da América Latina e alguns de seus problemas principais.” In BIELSHOWSKY, Ricardo (Org.). Cinqüenta anos de pensamento na Cepal. Rio de Janeiro: Record.

RICHARDSON, Harry W. (1975). Economia regional: teoria da localização, estrutura urbana e crescimento regional. Rio de Janeiro: Zahar. 
RODRÍGUEZ, Otavio (1981). Teoria do Subdesenvolvimento da CEPAL. Rio de Janeiro: Forense-Universitária.

ROSENSTEIN-RODAN, P. N. "Problemas de industrialização da Europa Oriental e SulOriental.” In AGARWALA, A. \& SINGH, S. (Org.). A Economia do Subdesenvolvimento. Rio de Janeiro: Forense, 1969.

ROSTOW, W. W. (1978). Etapas do crescimento econômico: um manifesto não-comunista. Rio de Janeiro: Zahar.

SEN, A. (1985). Commodities and capabilities. Amsterdam: North Holland.

SHNEIDER, Sérgio (2004). "A abordagem territorial do desenvolvimento rural e suas articulações externas." Sociologias, 6(11).

STRANGE, S. (1976). International monetaryrRelations. London: Oxford University Press.

TAVARES, Maria da Conceição (1973). Da substituição de importações ao capitalismo financeiro: ensaios sobre economia brasileira. Rio de Janeiro: Zahar.

VAINER, Carlos Bernardo (2001). "As escalas do poder e o poder das escalas: o que pode o poder local?” Cadernos IPPUR 15(2) 2001.

VEIGA, José Eli da (2002). “A face territorial do desenvolvimento.” Interações: Revista Internacional de Desenvolvimento Local 3(5).

WOOD, Ellen Meiksins (2003). Democracia contra capitalismo: a renovação do materialismo histórico. São Paulo: Boitempo.

Submissão: 28 de novembro de 2006

Primeira resposta: 21 de janeiro de 2007

Aceite: 22 de fevereiro de 2007 